$\underline{\text { Review Article }}$

\title{
DERIVATIVE UV SPECTROSCOPIC APPROACHES IN MULTICOMPONENT ANALYSIS-A REVIEW
}

\author{
SOWJANYA G. , GANAPATY S., SARA ALMAS \\ Department of Pharmaceutical Analysis, Institute of Pharmacy, GITAM Deemed to be University, Rushikonda, Visakhapatnam, Andhra \\ Pradesh, India \\ Email: tatinenijishnu@gmail.com
}

Received: 27 Oct 2018 Revised and Accepted: 31 Dec 2018

\begin{abstract}
The spectrophotometric multi-component analysis involves spectrum recording and mathematical equations. However, spectral interference poses a major limitation when mixture samples are encountered. To overcome this derivative spectrophotometry (DS) has been introduced for the resolution of overlapping peaks.

In this review modified methods like derivative quotient spectra, double divisor ratio spectra derivative method, double divisor means centering of ratio spectra method, derivative subtraction coupled with the constant multiplication method (DS-CM), amplitude subtraction (AS), modified amplitude subtraction (MAS), amplitude factor method (P-Factor), amplitude modulation method (AM), amplitude summation method (A-Sum), simultaneous derivative ratio spectrophotometry ( $\left.S^{1} D D\right)$, derivative compensation ratio via regression equation, differential dual wavelength ( ${ }^{1}$ DWL), differential derivative ratio ( $D^{1} \mathrm{DR}$ ), successive derivative subtraction method (SDS) and derivative transformation (DT) of derivative spectrophotometry theories and applications are reviewed.
\end{abstract}

These methods were applied to solve different complex pharmaceuticals mixtures. These developed methods were simple and cost-effective.

Keywords: Multicomponent analysis, Derivative spectrophotometry, Overlapping peaks, Derivative quotient spectra, Derivative subtraction, Simultaneous derivative ratio spectrophotometry, Derivative transformation, Complex pharmaceutical mixtures

(C) 2019 The Authors. Published by Innovare Academic Sciences Pvt Ltd. This is an open-access article under the CC BY license (http://creativecommons.org/licenses/by/4.0/) DOI: http://dx.doi.org/10.22159/ijpps.2019v11i2.30510

\section{INTRODUCTION}

Multi-drug therapy is an ancient phenomenon to combat interrelated symptoms of the diseased status of human beings. The pharmaceutical formulations with combinations of drugs have shown an increasing trend to counteract other symptoms specific to one drug formulation, and hence analytical chemist will have to accept the challenge of developing reliable methods for analysis of drugs in such formulation. Multicomponent analysis by using spectrophotometry has become an attractive tool for the analyst since microprocessor-based spectrophotometers join with cumbersome computers are widely used and have been performed for almost as long as single-component analysis. The spectrophotometric multi-component analysis can be applied where the spectra of drugs overlap. In such cases of overlapping spectra, multi-component analysis can be applied to any degree of spectral overlap provided that two or more spectra are not similar exactly [1].

Several spectrophotometric determination methods have been used for resolving mixtures of compounds with overlapping spectra, such as classical derivative spectrophotometry, Vierordt's method and its modified version, orthogonal function method, Fourier functions method, dual wavelength spectrophotometry, $\mathrm{pH}$-induced differential spectrophotometry, and least-square method, the multi-component analysis program, partial least squares regression (PLSR), principal component regression (PCR), multi-wavelength linear regression analysis (MLRA) and H-point standard addition method (HPSAM). But derivative spectrophotometry offers a range which is more reliable with respect to utility and sensitivity than normal spectrophotometry. Derivative UV spectroscopy has been widely used as a tool for quantitative analysis, characterization, and quality control in the agricultural, pharmaceutical, and biomedical fields. Derivative spectrophotometry (DS) is an analytical technique of great utility for resolving drugs mixtures with overlapping spectra. This outstanding feature coupled with zero-crossing, least-square deconvolution, or Fourier transforms data-processing techniques, has received increasing attention in single and multi-component quantitative analysis, especially in UV-absorbing matrices. DS has been applied successfully for the determination of drugs in the presence of their degradation's products [2]. Several review articles focussing on the simultaneous estimation of drugs in various formulations like tablets, injections, eye drops, etc., have been published in indexed (Science Direct, NCBI, Scopus, Pubmed) journals in the recent past (1992-2018) making it interesting to explore the variations in derivative spectrophotometry (searched for double divisor means, derivative subtraction, derivative transformation, etc.,) for better analytical interpretation in UV Visible spectroscopy.

When carrying out a multicomponent analysis the BouguerLambert-Beer law must be valid, i.e. absorbances must be additive over the concentration range, i.e. components must not interact. The greater the similarity between the spectra of individual components the more difficult and inaccurate the analysis where the choice of optimum wavelengths for the spectral analysis plays an important role. Interaction with the solvent must be excluded. Impurities absorbing in the same region can lead to considerable errors when measuring absorbances.

Values taken from the steep flanks of spectral bands should not be included in the analysis since an error in setting the wavelength causes a large error in absorbance. i.e. $\mathrm{dA} / \mathrm{d} \lambda$ is very large in this case. In contrast, $\mathrm{dA} / \mathrm{d} \lambda$ is small in the region of the absorption maxima, absorption minima, and pronounced shoulders. Very large or very small absorbances should be avoided since photometric accuracy is inferior in both cases.

The resolution of a spectrophotometer (slit program) should be set in such a way that the bands are optimally resolved. The measurement of the mixture must take place under the same instrumental conditions as that of the components [3].

\section{Beer-lambert law}

When a beam of light is passed through a transparent cell containing a solution of an absorbing substance, reduction of the intensity of light may occur [4].

$$
\mathbf{A}=\boldsymbol{\varepsilon b c}
$$

A-Absorbance; $\boldsymbol{\varepsilon}$-Molar absorptivity; b-Path length; c-Concentration 


\section{Principles of multi-component spectrometric analysis}

If a system is containing several absorbing components, it follows the principle of additivity of absorbances, i.e. the absorbance of a system containing several components is equal to the sum of absorbances of all individual components at a particular wavelength, and if no mutual interaction takes place between them, then

$$
\sum_{j=1}^{l=n} \varepsilon_{j} C_{j} L \lambda_{j}
$$

Where $\mathbf{q}_{\text {is }}^{\mathbf{i}}$ the molar absorptivity of the component 'i' at the $\lambda$ wavelength $\mathrm{j}$ and " $\mathrm{L}$ " is the path length.

\section{Derivative spectrophotometry (DS)}

The derivative method in UV-visible was introduced in 1953. However, as with any measurement technique, it is possible that derivative measurements, if used incorrectly, may actually introduce errors larger than would have been observed without its use. DS has become more practical owing to the increase in the resolving power of analytical instrument and the easier access to

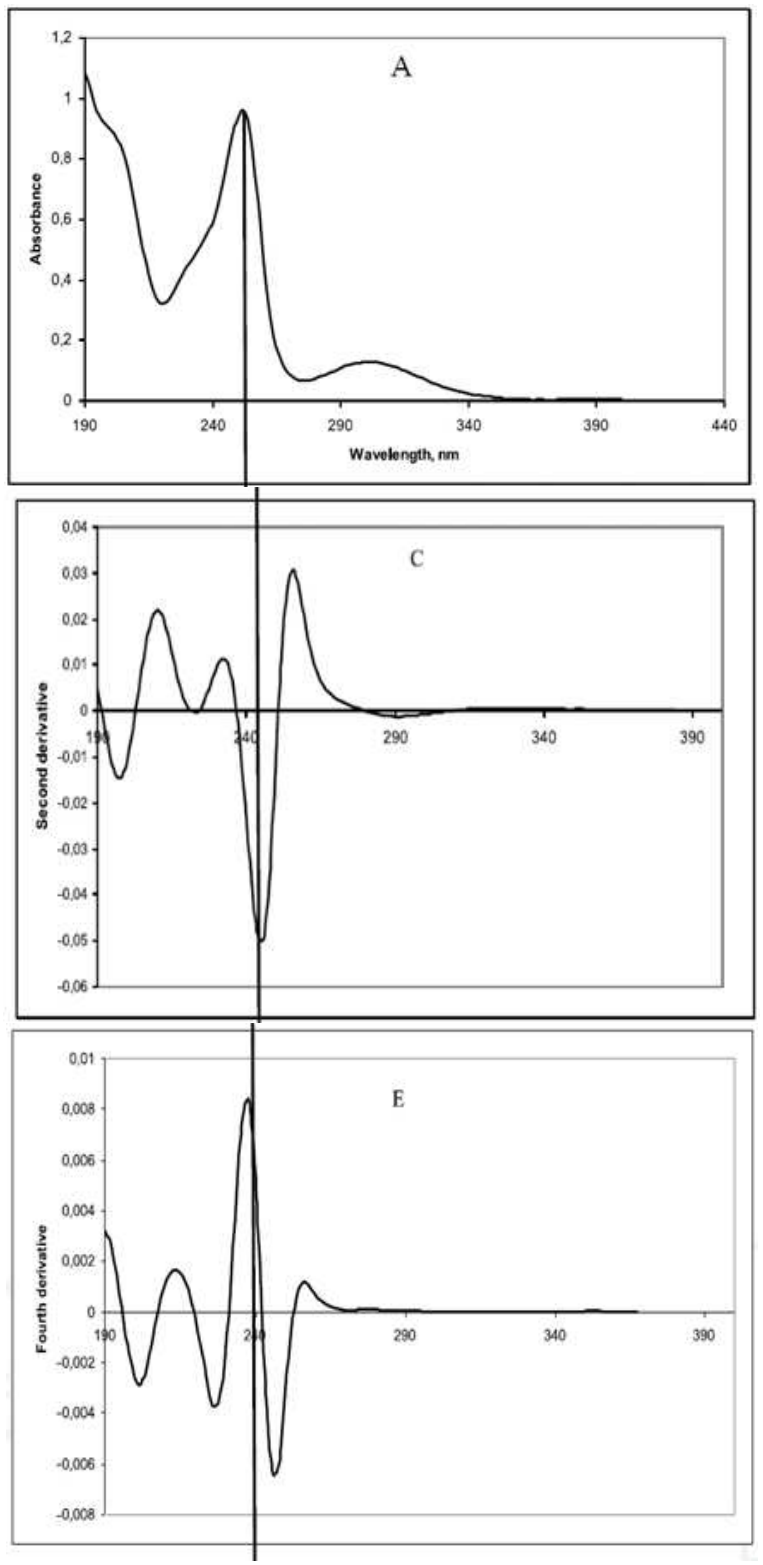

microcomputers with appropriate software, which allows the almost instantons generation of derivative spectra. This facility in the collection and treatment of the spectra has allowed analysis of multicomponent mixtures of analytes with strong overlapping spectra. The great interest towards DS is due to the increased resolution of spectral bands, allowing the detection and location of the wavelengths of poorly resolved components of complex spectra and reducing the effect of spectral background interferences. Understanding of the derivative concept will minimize this possibility. DS uses first or higher derivatives of absorbance with respect to wavelength for qualitative analysis and for quantification [5].

\section{Basic characteristics of derivative spectrophotometry}

a) The increase of spectral resolution.

b) Elimination of the influence of baseline shift and matrix interferences.

c) Enhancement of the detectability of minor spectral features.

d) Precise determination of the positions of absorption maxima [6]
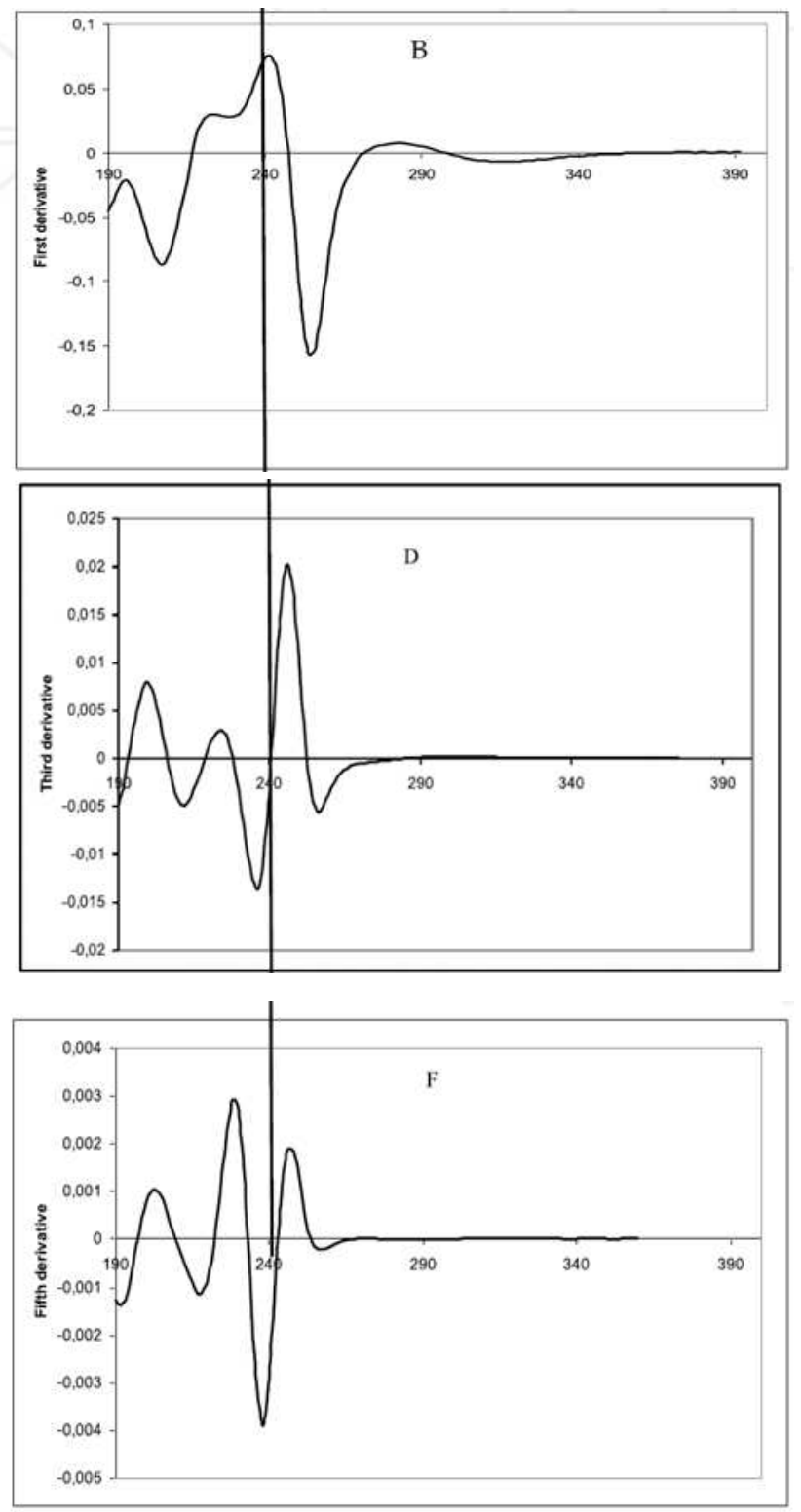

Fig. 1: Zero-order $(A)$ and consecutive derivative spectra $(B \rightarrow F)$ of an aqueous solution of promazine hydrochloride $(10 \mathrm{ppm})[6]$ 


\section{Basic theory and properties of derivative spectrophotometry}

DS is a technique which is based on derivative spectra of a basic, zero-order spectrum. Derivative spectrum can be expressed as:

$$
{ }^{\mathrm{n} D \mathrm{x}}, \boldsymbol{\lambda}=\mathrm{d}^{\mathrm{n} A} / \mathrm{d} \lambda^{\mathrm{n}}-\mathbf{f}(\boldsymbol{\lambda})
$$

or

$$
{ }^{n} \mathrm{Dx} \cdot \mathbf{v}=\mathrm{d}^{\mathrm{n}} \mathbf{A} / \mathbf{d}_{\mathrm{V}} \mathrm{n}=\mathbf{f}(\mathrm{v})
$$

Where, n-derivative order

${ }^{n} \mathrm{Dx}, \lambda$ or ${ }^{\mathrm{n}} \mathrm{Dx}, \mathrm{v}$-represents the value of n-orders derivative on an analyte $(\mathrm{x})$ at the analytical wavelength $(\lambda)$ at wave number $(\mathrm{v})$

A-absorbance.

DS keeps all features of classical spectrophotometry: Beer-Lambert law and law of additivity.

Beer-Lambert law differential form is expressed as:

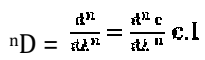

Where,

$\varepsilon$-molar absorption coefficient (L. $\mathrm{mol}^{-1} \cdot \mathrm{cm}^{-1}$ )

c-concentration of the analyte $\left(\mathrm{mol} \mathrm{L}^{-1}\right)$,

$l$ is the thickness of the solution layer $(\mathrm{cm})$.

The derivative spectrum of the n-component mixture is a sum of derivative spectra of individual components:

$$
{ }^{n} D_{\text {mix }}={ }^{n} D_{1}+{ }^{n} D_{2}+\ldots .{ }^{n} D_{n}
$$

A new feature of DS is the dependence of derivatization results on a geometrical characteristic of starting, zero-order spectrum. The shape and intensity of the resulted derivative spectrum depend on half-height width of the peak in the basic spectrum:

$$
{ }^{\mathrm{n}} \mathrm{D}=\mathbf{P}^{\mathrm{n}} \mathrm{A}_{\max } \mathrm{L}^{-1}
$$

Where,

$\mathrm{P}^{\mathrm{u}}$-polynomial described a run of the n-derivative curve,

L-width of half-heights of the peak of the zero-order spectrum.

\section{$\mathrm{N}$-derivative order}

Due to this property, broad zero-order spectra are quenched with the generation of higher orders of derivatives while narrow undergo amplification. If the zero-order spectrum possess two bands $\mathrm{A}$ and $\mathrm{B}$ which differ from their half-height's width (LB>LA), after a generation of n-order derivative a ratio of derivatives intensity can be expressed as:

$$
{ }^{n} D_{A} /{ }^{n} D_{B}=\left(L_{B} / l_{A}\right)^{n}
$$

This dependence leads to an increase in selectivity and/or sensitivity of the assay. It allows to use for analytical properties a narrow band, overlapped or completely hooded by a broad one.

The shape of the derivative spectrum is more complicated than its parent one (fig. 1). New maxima and minima appear as results of derivatization. The generation of $\mathrm{n}$-th order derivative spectrum produces $(n+1)$ new signals: an intense main signal and weaker bands, so-called satellite or wings signals. The position of maxima or minima depends on the order of derivative. The main extreme of derivative spectra of even order is situated at the same wavelength as a maximum in zero-order spectrum, but for 2, 6 and 10th order it becomes minimum in the derivative spectrum and for 4, 8 and 12th order it remains as a maximum (fig. 1). The point of initial maximum converts into the point of inflection in derivative spectra of odd order. A narrowing of new signals is observed during the generation of consecutive derivative spectra. This feature leads to narrowing bands and as a consequence of the separation of overlapped peaks.

\section{Derivative quotient spectra}

This method was developed by Salinas with a standard divisor when the spectra of the components are overlapped. Based on dividing the spectrum for a mixture into the standard spectra for each of the analyses and dividing the quotient to obtain an independent analyte concentration used as the divisor. The use of standard divisor minimizes experimental errors and background noises. Some coexisting compounds have no maximum or minimum at wavelengths are the advantage for the ratio spectra derivative spectroscopy compared to zero crossing derivative spectroscopy

A mixture of three compounds $\mathrm{A}, \mathrm{B}$ and $\mathrm{C}$ from the absorption spectrum is determined by the flowing equation:

$$
A_{\mathrm{M}, \lambda \mathrm{i}}=\varepsilon_{\mathrm{A}, \lambda \mathrm{i}} \mathrm{C}_{\mathrm{A}}+\varepsilon_{\mathrm{B}, \lambda \mathrm{i}} \mathrm{C}_{\mathrm{B}}+\varepsilon_{\mathrm{C}, \lambda \mathrm{i}} \mathrm{C}_{\mathrm{C}}
$$

Where,

Path length-1

$A_{M M A}-a$ bsorbance value of the mixture, at $\lambda_{\mathrm{i}}$.

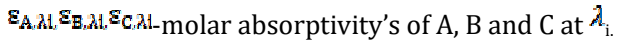

$\mathrm{C}_{\mathrm{A}}, \mathrm{C}_{\mathrm{B}}, \mathrm{C}_{\mathrm{C}}-$ molar concentrations of $\mathrm{A}, \mathrm{B}$ and $\mathrm{C}$.

Dividing the spectrum by the spectrum of a standard solution of one of the substance $\mathrm{A}$ of concentration $\mathrm{C}_{\mathrm{A}}$ i.e., by

$$
\mathbf{A}_{A, \lambda \mathbf{I}}^{\circ}=\varepsilon_{A, \lambda 1}^{\circ}, \mathbf{C}_{\AA}^{\circ} \text {. }
$$

Obtain,

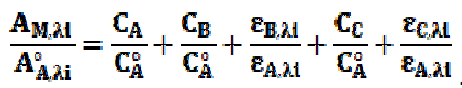
Eq. 3

First derivative of the spectrum ratio gives

$$
\frac{\mathrm{d}}{\mathrm{d} \lambda}\left(\frac{\mathrm{A}_{\mathrm{M}, \lambda \mathrm{i}}}{\mathrm{A}_{\mathrm{A}, \lambda \mathrm{i}}^{\circ}}\right)=\frac{\mathrm{C}_{\mathrm{B}}}{\mathrm{C}_{\AA}} \frac{\mathrm{d}}{\mathbf{d} \lambda}\left(\frac{\varepsilon_{\mathrm{B}, \lambda \mathrm{i}}}{\varepsilon_{\mathrm{A}, \lambda}}\right)+\frac{\mathrm{C}_{\mathrm{C}}}{\mathbf{C}_{\AA}^{\circ}} \frac{\mathbf{d}}{\mathbf{d} \lambda}\left(\frac{\varepsilon_{\mathrm{C}, \lambda \mathrm{i}}}{\varepsilon_{\mathrm{A}, \lambda \mathrm{i}}}\right)
$$

if $\mathbf{c}_{\mathbf{C}}=\mathbf{0}$ have the binary mixture of $\mathrm{A}$ and $\mathrm{B}$

In case of the spectrum:

$$
\frac{\mathrm{d}}{\mathrm{d} \lambda}\left(\frac{A_{\mathrm{M}, \lambda \mathrm{A}}}{\mathrm{A}_{\mathrm{A}, \lambda \mathrm{A}}^{\circ}}\right)=\frac{\mathrm{C}_{\mathrm{B}}}{\mathrm{C}_{\mathrm{A}}^{0}} \frac{\mathrm{d}}{\mathrm{d} \lambda}\left(\frac{\varepsilon_{\mathrm{B}, \lambda 1}}{\varepsilon_{\mathrm{A}, \lambda \mathrm{i}}}\right)
$$

From the equation (Eq.5) the derivative ratio spectrum of binary mixture is depending only on the value of $C_{B}$ and $\mathrm{C}_{\mu}^{\mathrm{L}}$, indepedent of the value of $\mathrm{C}_{\mathrm{A}}$ in the binary mixture.

Binary mixtures of diazepam (D) and otilonium (O) are analyzed by ratio spectra DS. It is based on dividing the absorption spectrum of the mixture of (DandO) into the standardized spectra for each of the analytes. Derivatization of obtained spectra gives derivative spectra that is independent to the analyte concentration used as the divisor. (fig. 2) shows the first derivatives of the ratio spectra of different concentrations.

By a combination of zero crossing derivative technique and derivative ratio, spectra can resolve the ternary mixture. (Eq. 4) indicates that the derivative ratio spectrum of the ternary mixture is dependent only on $\mathrm{C}_{\mathrm{B}}, \mathrm{C}_{\mathrm{C}}$ and $\mathrm{C}_{\mathrm{A}}^{\mathrm{a}}$ and independent of the value of $\mathrm{C}_{\mathrm{A}}$ in the binary mixture. The concentration of $\mathrm{B}$ and $\mathrm{C}$ can be determined by the zero-crossing method by measuring the derivative value at adequate wavelengths. The second derivative of (Eq.3) gives

$$
\frac{d^{2}}{d \lambda^{2}}\left(\frac{A_{M, \lambda 1}}{A_{A, \lambda 1}^{\circ}}\right)=\frac{C_{B}}{C_{A}^{\circ}} \frac{d^{2}}{d \lambda^{2}}\left(\frac{\varepsilon_{B, \lambda 1}}{\varepsilon_{A, \lambda i}}\right)+\frac{C_{C}}{C_{\AA}^{\circ}} \frac{d^{2}}{d \lambda^{2}}\left(\frac{\varepsilon_{C, \lambda 1}}{\varepsilon_{A, \lambda i}}\right)_{\text {E Eq. } 6}
$$

In this (Eq. 6) [9] the second derivative ratio spectrum is dependent only on $C_{B}$, C and $C_{A}^{\circ}$ [7]

\section{Applications}

This method has been used in the determination of Olmesartan medoxomil, Hydrochlorothiazide and Amlodipine besylate, antihypertensive drugs in a ternary mixture with good precision and this method minimizes experimental errors, background noises and do not need tedious extraction procedures or complicated instruments [8]. 


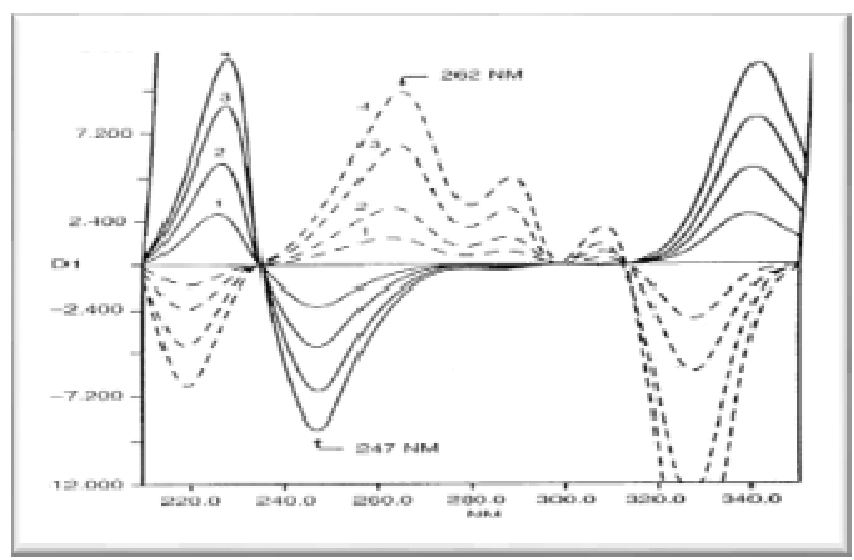

Fig. 2: First derivative spectra of the ratio spectra of (D and 0 ) $D$ is---and 0 - [7]

\section{Double divisor ratio spectra derivative method}

This method was proposed by Dinc. It is a new technique for the determination of three compounds in ternary mixtures. This method based on the derivative of ratio spectrum obtained by dividing the absorption spectrum of the ternary mixtures by a standard spectrum of a mixture of two of the three components in the main mixture. The concentration of three compounds in the mixture was determined by using their respective calibration graphs that were obtained by measuring the amplitude at either the maximum or minimum wavelengths selected $[10,11]$.

In this method, to determine species $\mathrm{A}$, the absorption spectra of the mixture containing $\mathrm{AB}$ and $\mathrm{C}$ were divided by the sum of the spectra of $\mathrm{B}$ and $\mathrm{C}$ as "double divisor" and the ratio spectra were obtained. First derivate of ratio spectra was calculated. The amplitudes measured at selected wavelength $\boldsymbol{x}_{\mathbf{i}}$ were dependent only on the concentration's values of $\mathrm{C}_{\mathrm{A}}$ and $\mathrm{C}_{\mathrm{C}}^{*} \mathrm{C}^{\mathrm{s}}$ is the standard concentration), but were independent of the concentration values $C_{B}$ and $C_{C}$ in the ternary mixture. The mathematical expression of this procedure is shown in the following equation:

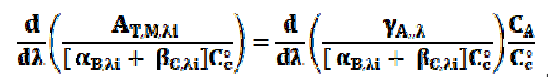

The amplitudes measured, $d / d \lambda\left({ }_{\mathrm{T}, \mathrm{M}, \lambda 1} /\left(\left[\alpha_{\mathrm{B}, \lambda 1}+\beta_{\mathrm{C}, \lambda 1}\right] \mathrm{C}_{2}^{\circ}\right)\right.$ was drawn as a graph versus concentration of species $\mathrm{A}$, and a straight line was obtained. By using the calibration graph, one could determine the $\mathrm{A}$ species in the mixture of $\mathrm{A}, \mathrm{B}$ and $\mathrm{C}$.

Where, $\gamma_{\mathrm{A}, \lambda}, \alpha_{\mathrm{B}, \lambda 1}$ and $\beta_{\mathrm{C}, \lambda 1}$ are the molar absorptivity's of the species $\mathrm{A}, \mathrm{B}$ and $\mathrm{C}$ respectively.

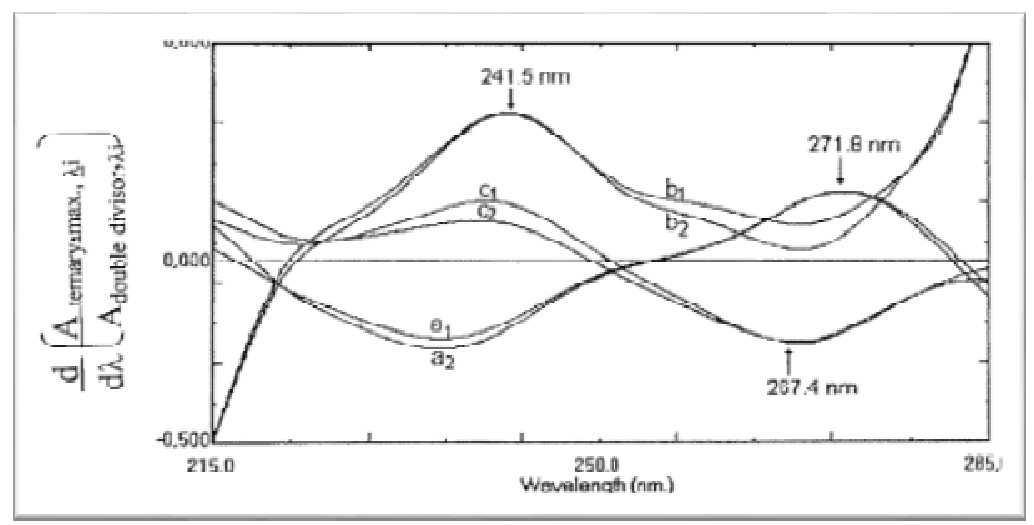

Fig. 3: Coincident spectra of the first derivative of the ratio [9], $a_{1}=$ pure acetylsalicylic acid (ASA) $a_{2}=$ ternary mixture (ASAC) as a double divisor $b_{1}=$ pure paracetamol (PAR) $b_{2}=$ ternary mixture (ASCA) as a double divisor, $c_{1}=$ pure (ASCA), $c_{2}=$ ternary mixture (ASA)

\section{Applications}

This method was used in the estimation of a ternary mixture Guaifenesin, Dextromethorphan HBR, and Diphenhydramine $\mathrm{HCl}$ in pharmaceutical dosage forms [12].

\section{Double divisor means centering of ratio spectra method}

If a mixture of five compounds is considered and Beer's law is obeyed for all compounds over the whole wavelength range used as given in the following example $[13,14]$ consisting of paracetamol (PA), methylparaben (MP), propylparaben (PP), chloropheniramine maleate $(\mathrm{CH})$ and pseudoephedrine hydrochloride (PS), then

$A_{m}=\alpha_{P A} C_{P A}+\alpha_{M P} C_{M P}+\alpha_{P P} C_{P P}+\alpha_{C H} C_{C H}+\alpha_{P S} C_{P S}$ .. Eq. 8

Where,

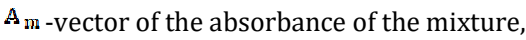

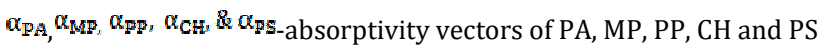
$\mathrm{C}_{\mathrm{PA}}, \mathrm{C}_{\mathrm{MP}}, \mathrm{C}_{\mathrm{PP}}, \mathrm{C}_{\mathrm{u} H a n d} \mathrm{C}_{\mathrm{PS}}-$ concentrations of PA, MP, PP, CH and PS.

Absorptivity A: $(1 \%, 1 \mathrm{~cm})$ values were calculated by using the absorbance for zero-order spectra for each of the compounds in the five-component mixture.

Eq.8 is divided by $\quad \alpha_{\mathrm{MP}} \mathrm{C}_{\mathrm{MP}}^{\circ}+\alpha_{\mathrm{pp}} \mathrm{C}_{\mathrm{Pp}}^{\circ} \quad\left(\mathrm{C}_{\mathrm{MP}}^{\circ}=\mathrm{C}_{\mathrm{pp}}^{\circ}=1 \mu \mathrm{g} / \mathrm{ml}\right)$ corresponding to the spectrum of a standard solution of CMP and CPP the first ratio spectrum is obtained

$$
\mathbf{x}=\frac{\mathbf{A}_{\mathrm{m}}}{\boldsymbol{\alpha}_{\mathrm{MP}}+\boldsymbol{\alpha}_{\mathrm{PP}}}
$$


$\mathrm{C}_{\mathrm{MP}}$ and $\mathrm{C}_{\mathrm{Pp}}$ are equal and in the real sample, standard addition method is used $\left(\mathrm{C}_{\mathrm{MP}}=\mathrm{C}_{\mathrm{PP}}+\mathrm{C}_{\mathrm{PP}}, \mathrm{x}\right)$

$$
\begin{gathered}
\mathbf{x}=\frac{\boldsymbol{A}_{\mathrm{m}}+\alpha_{\mathrm{PP}} \mathbf{C}_{\mathrm{PP}, \mathbf{x}}}{\boldsymbol{\alpha}_{\mathrm{MP}}+\alpha_{\mathrm{PF}}} \\
\mathbf{x}=\frac{\alpha_{\mathrm{MP}} \mathrm{C}_{\mathrm{MP}}+\alpha_{\mathrm{PP}}\left[\mathbf{C}_{\mathrm{PP}}+\mathbf{C}_{\mathrm{PP},} \mathbf{x}\right.}{\alpha_{\mathrm{MP}}+\alpha_{\mathrm{PP}}}+\frac{\alpha_{\mathrm{PA}} \mathbf{C}_{\mathrm{PA}}}{\alpha_{\mathrm{MP}}+\alpha_{\mathrm{PP}}}+\frac{\alpha_{\mathrm{CH}} \mathbf{C}_{\mathrm{CH}}}{\alpha_{\mathrm{MP}}+\alpha_{\mathrm{PP}}}+\frac{\alpha_{\mathrm{PS}} \mathbf{C}_{\mathrm{PS}}}{\alpha_{\mathrm{MP}}+\alpha_{\mathrm{PP}}} \ldots
\end{gathered}
$$

Equation 9 and 10 are mean centred, therefore

$$
m c x=m c \frac{\alpha_{P A} \mathbf{C}_{P A}}{\alpha_{M P}+\alpha_{P P}}+m c \frac{\alpha_{C H} \mathbf{c}_{C H}}{\alpha_{M P}+\alpha_{P P}}+m c \frac{\alpha_{P S} C_{P S}}{\alpha_{M F}+\alpha_{P P}} .
$$

\section{$\alpha_{\mathrm{CH}}$}

By dividing the (Eq.11) with $\overline{\boldsymbol{\alpha}_{\mathrm{MP}}+\boldsymbol{\alpha}_{\mathrm{PP}}}$, the second ratio spectrum is obtained

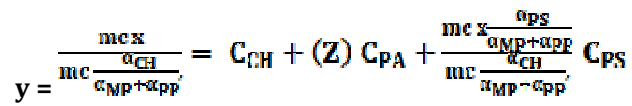

$$
\begin{aligned}
& m c y=m c Z c_{P A 0}+m c \frac{\text { me } \frac{\alpha_{P S}}{\alpha_{M P}+\alpha_{P P}}}{m c \frac{\alpha_{C H}}{\alpha_{M P}+\alpha_{P P}}}
\end{aligned}
$$

Finally, we obtain the third ratio spectrum

$$
\text { mc } \frac{\text { mc } y}{m c Z}=\text { (constant) } \mathbf{C}_{\mathbf{P S}}
$$

(Eq. 13) is the mathematical foundation of multicomponent analysis which permits the determination of the concentration of each compound without interference from the other components of the mixture [10].

\section{Applications}

This method was used in the routine simultaneous determination of Paracetamol (PA), Methylparaben (MP), Propylparaben (PP), Chlorpheniramine maleate (CH) and Pseudoephedrine hydrochloride (PS) in a pharmaceutical syrup. This method has the advantages of high sensitivity, extremely low detection limit and good selectivity.

\section{Derivative subtraction coupled with the constant multiplication method (DS-CM)}

In derivative subtraction, the ratio spectra were used from which the selected divisor allowed low noise and high sensitivity. This is the recent developed method in resolution technique in the multicomponent analysis [15]. If we had a mixture of $\mathrm{X}, \mathrm{Y}$ and $\mathrm{Z}$, where $\mathrm{Z}$ was more extended than $\mathrm{Y}$ and consequently $\mathrm{Y}$ was more extended than $X$ so we could eliminate them one by one using successive ratio subtractions. Then $\mathrm{X}$ was determined.

So, the determination of $\mathrm{X}$ could be done by successive ratio subtraction dividing the spectrum of the mixture by a certain concentration of $\mathrm{Z}$ as a divisor ( $\mathrm{Z}$ '). The division would give a new spectrum that was represented as follows:

$$
\begin{aligned}
& \quad \frac{(\mathbf{X}+\mathbf{Y}+\mathbf{Z})}{\mathbf{Z}^{\prime}}=\left(\frac{\mathbf{X}}{\mathbf{Z}^{\prime}}\right)+\left(\frac{\mathbf{Y}}{\mathbf{Z}^{\prime}}\right)+\left(\frac{\mathbf{Z}}{\mathbf{Z}^{\prime}}\right) \\
& \frac{(\mathbf{X}+\mathbf{Y}+\mathbf{Z})}{\mathbf{Z}^{\prime}}=\frac{(\mathbf{X}+\mathbf{Y})}{\mathbf{Z}^{\prime}}+\text { Constant }
\end{aligned}
$$

The constant could be determined directly from the $(\mathrm{X}+\mathrm{Y}+\mathrm{Z}) / \mathrm{Z}^{\prime}$ spectrum by the straight line that was parallel to the wavelength axis in the region where $\mathrm{Z}$ was extended.

For obtaining the first component $(\mathrm{Z})$, constant multiplication method had been established as a new approach in which $\mathrm{Z}$ could be determined by multiplication of $\mathrm{Z}^{\prime}$ divisor by the previously obtained constant $\mathrm{Z} / \mathrm{Z}$, therefore we could obtain the $\mathrm{D}^{\circ}$ curve of $\mathrm{Z}$. This could be summarized as follows:

$$
\mathbf{z}=\left(\frac{\mathbf{Z}}{\mathbf{Z}^{\prime}}\right) \mathbf{z}^{\prime}
$$

The concentration of $\mathrm{Z}$ was calculated from the corresponding regression equation (obtained by plotting the absorbance values of the zero order curves of $\mathrm{Z}$ at its $\lambda_{\max }$ against the corresponding concentrations).
If we subtract the measured value of the constant from the ratio spectrum Eq. (14), then multiply the new spectrum by Z', we obtain the spectrum of $\mathrm{X}+\mathrm{Y}$ as the binary mixture. This could be summarized in the following equations:

$$
\begin{gathered}
\frac{(\mathbf{X}+\mathbf{Y})}{\mathbf{Z}^{\prime}}+\text { Constant - Constant } \\
\frac{(\mathbf{X}+\mathbf{Y})}{\mathbf{Z}^{\prime}} \times \mathbf{Z}^{\prime}=(\mathbf{X}+\mathbf{Y})
\end{gathered}
$$

The obtained spectrum was successively divided by $\mathrm{Y}$ as a divisor $\left(Y^{\prime}\right)$. The constant could be determined directly from the $(\mathrm{X}+\mathrm{Y}) / \mathrm{Y}^{\prime}$ spectrum by the straight line that was parallel to the wavelength axis in the region where $Y$ was extended.

$$
\frac{(\mathbf{X}+\mathbf{Y})}{\mathbf{Y}^{\prime}} \times \mathbf{Y}^{\prime}-\left(\frac{\mathbf{X}}{\mathbf{Y}^{\prime}}\right)+\left(\frac{\mathbf{Y}}{\mathbf{V}^{\prime}}\right) \ldots \ldots \ldots . \text { Eq. } 15
$$

For obtaining the second component $(\mathrm{Y})$, Constant multiplication method was established as a new approach in which Y could be determined by multiplication of $\mathrm{Y}^{\prime}$ divisor by the previously obtained constant $Y / Y^{\prime}$, therefore we could obtain the $D^{\circ}$ curve of $Y$. This could be summarized as follows:

$$
\mathbf{Y}=\left(\frac{\mathbf{Y}}{\mathbf{Y}^{\prime}}\right) \mathbf{Y}^{\prime}
$$

The concentration of $\mathrm{Y}$ was calculated from the corresponding regression equation (obtained by plotting the absorbance values of the zero order curves of $\mathrm{Y}$ at its $\lambda$ max against the corresponding concentrations). If we subtracted the measured value of the constant $\mathrm{Y} / \mathrm{Y}^{\prime}$ from the ratio spectrum Eq. (15), then multiplied the spectrum by $\mathrm{Y}^{\prime}$, we obtain $\mathrm{D}^{\circ}$ curve of $\mathrm{X}$. This could be summarized in the following equations:

$$
\begin{gathered}
\frac{\left(\mathbf{X}+\mathbf{Y}^{\prime}\right)}{\mathbf{Z}^{\prime}}+\text { Constant }- \text { Constant }=\left(\frac{\mathbf{X}}{\mathbf{Y}^{i}}\right) \\
\left(\frac{\mathbf{Y}}{\mathbf{Y}^{i}}\right) \mathbf{Y}^{\prime}=\mathbf{X} \ldots \ldots \ldots . . \text { Eq. } 16
\end{gathered}
$$

The concentration of $\mathrm{X}$ was calculated using the regression equation representing the linear relationship between the absorbance at its $\lambda_{\max }$ versus the corresponding concentration of $\mathrm{X}$.

\section{Applications}

It is used for analysis of binary and ternary pharmaceuticals mixture lidocaine hydrochloride dexamethasone acetate and calcium dobesilate.

\section{Amplitude subtraction (AS)}

This method can be used in case of having a mixture of $\mathrm{X}$ and $\mathrm{Y}$, where the first derivative spectra of $Y$ shows two peaks at two different wavelengths $\left(\lambda_{1}\right.$ and $\left.\lambda_{2}\right)$, and the first derivative spectra of $\mathrm{X}$ shows one peak that is overlapped with $\mathrm{Y}$ peak of at $\lambda_{1}$, while shows no contribution at $\lambda_{2}$ [16]. Different concentrations of $Y$ were used to construct the regression equation representing relationship between the two amplitudes at $\lambda_{1}$ and $\lambda_{2}$

$$
\mathrm{P}_{1}=\text { Slope } \mathrm{P}_{2}+\text { intercept }
$$

Where P1 is the peak amplitude at $\lambda 1$ and P2 is the peak amplitude at $\lambda 2$. The mixture is scanned and first derivative spectrum is determined. The peak amplitude of the mixture at $\lambda 2$, which represent the peak amplitude of $Y$ only is recorded. By substituting it in the previous equation we can calculate the peak amplitude of $Y$ at $\lambda 1$. The peak amplitude of $X$ can be determined by subtracting the calculated peak amplitude of $Y$ at $\lambda 1$ from the recorded peak amplitude at the same wavelength. Two regression equations are constructed, one representing a linear relationship between the peak amplitude of the first derivative spectra at $\lambda 1$ versus the corresponding concentration of $\mathrm{X}$ and can be used for calculation of concentration of drug $\mathrm{X}$, and the other representing a linear relationship between the peak amplitude of the first derivative spectra at $\lambda 2$ versus the corresponding concentration of $Y$ and can be used for calculation of concentration of drug Y.

\section{Applications}

Dosage forms containing mixtures of Simvastatin phosphate and Metformin $\mathrm{HCl}$ [17], Lidocaine $\mathrm{HCl}$, Calcium dobesilate and Dexamethasone acetate [16] were analysed using amplitude subtraction 
[16]. The proposed methods are also suitable and valid for application in laboratories lacking liquid chromatographic instruments [18].

\section{Limitations}

- Critical measurements of the amplitudes at the selected wavelength. • Greatly affected by wavelength increment. • The high noise which affects the signal to noise ratio. - Only applied for partially overlapped spectra of X and Y [19].

\section{Modified amplitude subtraction (MAS)}

In case of having a mixture of two drugs $\mathrm{X}$ and $\mathrm{Y}$, and the first derivative spectra of both drugs show overlapped peaks at $\lambda_{1}$, while only the first derivative spectra of $\mathrm{Y}$ show a peak at $\lambda_{2}$. Two calibration curves are constructed relating the peak amplitude of $Y$ at $\lambda_{1}$ verses the corresponding concentration of $Y$ (equation 14) and the peak amplitude of $\mathrm{Y}$ at $\lambda_{2}$ verses the corresponding concentration of $Y$ (equation 15). The mixture is scanned and the first derivative spectrum of the mixture is determined. First, the peak amplitude of mixture at $\lambda_{2}$ is recorded and by substituting it in equation 15 the concentration of $\mathrm{Y}$ can be calculated. Then the calculated concentration is substituted in equation 14 to determine the peak amplitude of $\mathrm{Y}$ in the mixture at $\lambda_{1}$. By subtracting the postulated peak amplitude at $\lambda_{1}$ from the recorded peak amplitude of the mixture at the same wavelength, the peak amplitude of drug $X$ can be determined. A regression equation is constructed representing a linear relationship between the peak amplitude of the first derivative spectra at $\lambda_{1}$ versus the corresponding concentration of $\mathrm{X}$ allowing the determination of the concentration of drug X [16].

\section{Applications}

This method can be applied for severely overlapped spectra of X and Y. It is used in the determination of Sitagliptin phosphate with Metformin hydrochloride in tablets [17]. Lidocaine $\mathrm{HCl}$, Calcium Dobesilate, and Dexamethasone Acetatein their binary mixture were conveniently quantified using the modified amplitude subtraction method [16].

This is considered to be advantageous over amplitude subtraction as the only requirement is the presence of one wavelength where both drugs are severely overlapped and it gives the chance of using any conventional spectrophotometric method for the determination of one of the two components and so it is more flexible. In addition, there is no need for a special regression equation to be computed; it requires only the construction of two calibration curves relating the peak amplitudes of the pure drugs at the overlapping wavelength versus their corresponding concentrations.

\section{Limitations}

- Critical measurements of the amplitudes at the selected wavelength. • Greatly affected by wavelength increment. • The high noise which affects the signal to noise ratio [19].

\section{Amplitude factor method (P-Factor)}

This method can be used in case of having a mixture of $\mathrm{X}$ and $\mathrm{Y}$, where the first derivative spectra of $Y$ shows two peaks at two different wavelengths $\left(\lambda_{1}\right.$ and $\left.\lambda_{2}\right)$, and the first derivative spectra of $\mathrm{X}$ shows one peak that is overlapped with $\mathrm{Y}$ peak of at $\lambda_{1}$, while shows no contribution at $\lambda_{2}$

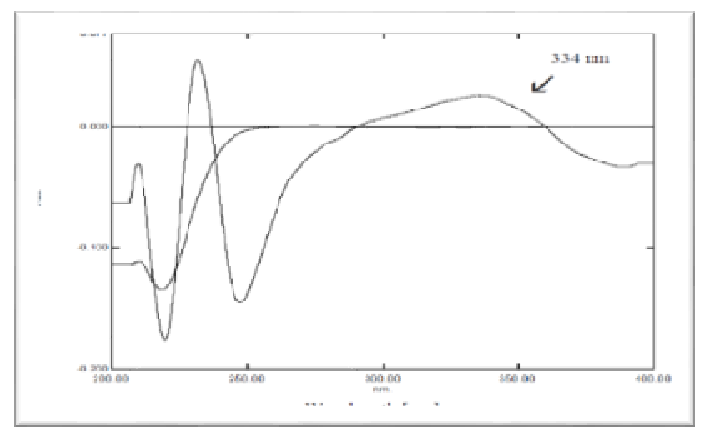

Fig. 4: First derivative spectra of perindopril (PER) and amlodipine (AML) [20]
The spectra are overlapped at wavelength $219 \mathrm{~nm}$, while at $334 \mathrm{~nm}$ there is no contribution of PER, only AML is detected. The average value of the amplitude factor of pure AML at different concentrations was calculated using the following equation:

$$
\left(\mathrm{P}_{219} \mathrm{~nm} / \mathrm{P}_{334} \mathrm{~nm}=\mathrm{P}_{1} / \mathrm{P}_{2}\right)
$$

The value was found to be 6.7471 . The mixture was scanned and the first derivative spectrum was determined. Since the peak amplitude of the mixture at $334 \mathrm{~nm}$ represents only AML, as there is no contribution of PER at this wavelength, them the amplitude of PER can be determined using the following equation:

$$
\mathrm{P}_{219} \mathrm{~nm}(\mathrm{PER})=\mathrm{P}_{219} \mathrm{~nm}(\mathrm{PER}+\mathrm{AML})-\left(\mathrm{P}_{1} / \mathrm{P}_{2}\right) \times \mathrm{P}_{334} \mathrm{~nm}(\mathrm{PER}+\mathrm{AML})
$$

Where; $\mathrm{P}_{1} / \mathrm{P}_{2}$ is the amplitude factor of pure, AML $\left(\mathrm{P}_{219} \mathrm{~nm} / \mathrm{P}_{334}\right.$ $\mathrm{nm}=6.7471), \mathrm{P}_{219} \mathrm{~nm}(\mathrm{PER}+\mathrm{AML})$ is the amplitude of the mixture at $219 \mathrm{~nm}, \mathrm{P}_{334} \mathrm{~nm}(\mathrm{PER}+\mathrm{AML})$ is the amplitude of AML only at $334 \mathrm{~nm}$. The concentrations of PER and AML were calculated from the corresponding regression equations obtained by plotting the amplitude values of the first derivative spectra at $219 \mathrm{~nm}$ and 334 $\mathrm{nm}$ versus the corresponding concentrations, respectively.

\section{Applications}

This method is used in the determination of Lidocaine $\mathrm{HCl}$, Calcium dobesilate, and Dexamethasone acetate [16]. Literature also revealed the quantitative analysis of Chloramphenicol, Dexamethasone sodium phosphate and Tetryzoline $\mathrm{HCl}$ [21] in eye drops using P-factor method. Simultaneous estimation of Sitagliptin phosphate and metformin $\mathrm{HCl}$ [17], Omeprazole, Tinidazole and Doxycycline [22] in dosage forms were also reported by this method.

This method also has the same limitations as amplitude subtraction method.

\section{Amplitude modulation method (AM)}

The method is a novel ratio spectrum manipulating method using the normalized spectrum of the divisor obtained by dividing certain spectrum of $Y^{\prime}$ component by its concentration [21]. For a mixture of $\mathrm{X}$ and $\mathrm{Y}$, where $\mathrm{Y}$ is more extended than $\mathrm{X} ; \mathrm{X}$ and $\mathrm{Y}$ shows is absorptive point at the zero spectrum and consequently is retained as an isosbestic point at the ratio spectrum. At, $\lambda_{\text {iso }}$

$$
\left[\mathbf{A}_{\mathrm{m}}\right]=\left[\mathbf{A}_{\mathbf{X}}\right]+\left[\mathbf{A}_{\mathrm{Y}}\right]
$$

$A_{m}, A_{x}, A_{y}$ are the absorbance values of the mixture, component $X$ and component $Y$ at isoabsorptive point, respectively. Therefore,

$$
\left[\mathbf{A}_{\mathrm{m}}\right]=\left[\mathbf{a}_{\mathbf{X}} \mathbf{C}_{\mathbf{X}}\right]+\left[\mathbf{a}_{\mathbf{Y}} \mathbf{C}_{\mathbf{Y}}\right]
$$

Divide the previous equation with spectrum of $Y^{\prime}$ as a divisor to obtain the isosbestic point of the ratio spectrum (at the same wavelength of the isoabsorptive point present in zero order spectra), so the following equation was obtained:

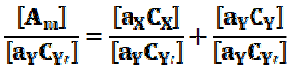

$$
\begin{aligned}
& \mathbf{P}_{\mathrm{m}}=\boldsymbol{P}_{\mathrm{X}}+\mathbf{P}_{\mathrm{Y}}
\end{aligned}
$$

$\mathrm{P}_{\mathrm{m}}, \mathrm{P}_{\mathrm{X}}$ and $\mathrm{P}_{\mathrm{Y}}$-The amplitude of constant (PY) [aY $\left.\mathrm{C}_{\mathrm{Y}} / \mathrm{a}_{\mathrm{Y}} \mathrm{C}_{\mathrm{Y}}\right]$ can be measured directly from the ratio spectrum in the region where $\mathrm{Y}$ is extended since the constant is a straight line parallel to the wavelength axis in this region.

Upon using the normalized spectrum of $Y^{\prime}$, the following equation was obtained:

$$
\begin{gathered}
\mathbf{P}_{\mathrm{m}}=\mathbf{P}_{\mathrm{X}}+\mathbf{P}_{\mathrm{Y}} \\
\mathbf{P}_{\mathrm{m}}=\frac{\left\lfloor\mathrm{a}_{\mathrm{X}} \mathbf{C}_{\mathrm{X}}\right\rfloor}{\left[\mathrm{a}_{\mathrm{Y}}\right]}+\frac{\left\lfloor\mathrm{a}_{\mathrm{Y}} \mathbf{C}_{Y}\right\rfloor}{\left[\mathrm{a}_{\mathrm{Y}}\right]} \\
\mathbf{P}_{\mathrm{m}}=\frac{\left[\mathrm{a}_{\mathrm{X}} \mathbf{C}_{\mathrm{X}}\right]}{\left[\mathrm{a}_{\mathrm{Y}}\right]}+\text { constant } \\
\mathbf{P}_{\mathrm{y}}=\frac{\left[\mathrm{a}_{\mathrm{Y}} \mathbf{C}_{\mathrm{Y}}\right]}{\left[\mathrm{a}_{\mathrm{Y}}\right]} \\
\mathbf{P}_{\mathrm{y}}=\mathbf{C}_{\mathrm{Y}}
\end{gathered}
$$


The recorded amplitude of the constant was modulated to concentration, so it was representing the concentration of $\mathrm{Y}\left[\mathrm{C}_{\mathrm{Y}}\right]$. $(\mathrm{C}$ recorded of $\mathrm{Y}$ ). For the determination of $\mathrm{X}$, we subtract the measured value of the constant from the ratio spectrum at $\lambda_{\text {iso. }}$.

$$
\begin{gathered}
\mathbf{P}_{\mathrm{x}}=P_{\mathrm{m}}-\mathbf{P}_{\mathrm{Y}} \\
\mathbf{P}_{\mathrm{x}}=\left\{\frac{\left[\mathrm{a}_{\mathrm{x}} \mathbf{C}_{\mathrm{x}}\right]}{\left[\mathrm{a}_{\mathrm{y}}\right]}+\text { constant }\right\}-\text { constant } \\
\mathbf{P}_{\mathrm{x}}=\left\{\frac{\left[\mathrm{a}_{\mathrm{x}} \mathbf{C}_{\mathrm{x}}\right]}{\left[\mathrm{a}_{\mathrm{y}}\right]}\right\}
\end{gathered}
$$

Since, at the isosbestic point $\mathbf{a}_{\mathrm{x}}=\mathbf{a}_{\mathrm{y}}, \mathbf{P}_{\mathbf{x}}=\mathbf{c}_{\mathbf{x}}$

This obtained amplitude of ratio spectrum was modulated to concentration and it was representing the concentration of $\mathrm{X}[\mathrm{Cx}]$. (C recorded of X).

To eliminate any error, those recorded concentrations of $\mathrm{X}$ and $\mathrm{Y}$ could be corrected to the actual concentrations by using the following regression equation:

$$
\mathrm{C}_{\text {recorded }}=\text { slope } \mathrm{C}+\text { intercept }
$$

The slope was found to be around unity and intercept was found to be around zero.

Where; $\mathrm{C}$ recorded represents the recorded amplitudes corresponding to the concentrations of $\mathrm{X}$ or $\mathrm{Y}$ that were obtained from the ratio spectrum using the normalized spectrum of $\mathrm{Y}^{\prime}$ as a divisor and $\mathrm{C}$ represents the corresponding concentrations of X or $\mathrm{Y}$.

\section{Applications}

This method has advantage over the isoabsorpative point at zero order that it measures the concentration of both components with no need for another conventional method to measure one of the components in the mixture. This method has advantages over the newly developed absorbance subtraction method (AS) through using the normalized divisor, where the obtained amplitude at the ratio spectrum will directly represent the concentration of each component and so the risk of error upon the determination of absorbance factor of lower absorbance will be reduced through the elimination of the absorbance factor step. That is why the sensitivity of this method is better than AS method. This method was applied for the analysis of the ternary mixture of Chloramphenicol (CHL), Dexamethasone sodium phosphate (DXM) and Tetryzoline hydrochloride (TZH) in eye drops.

\section{Amplitude summation method (A-Sum)}

This novel method is applied for a mixture of $\mathrm{X}$ and $\mathrm{Y}$, where $\mathrm{X}$ and $\mathrm{Y}$ spectra show isoabsorptive point at the zero spectrum; while first derivative spectra (D) of $Y$ shows no contribution with that of $X$ at a certain wavelength. By calculating the first derivative spectra (D) of equal concentration of $\mathrm{X}$ and $\mathrm{Y}$, at equal path length, it was found that the D spectra intersect at an isosbestic point at the wavelength which shows the certain shift from the isoabsorptive point found in zero order spectra, so the following equation was obtained:

$$
\begin{aligned}
& D=\frac{d A}{d \lambda}=\frac{d a}{d \lambda} b c \\
& \text { At } \lambda_{\text {iso, }} D_{x}=D_{Y} \\
& \frac{d x}{d \lambda} b x c x=\frac{d y}{d \lambda}=b y c y
\end{aligned}
$$

For a mixture of both drugs, the amplitude at that wavelength $\left(\lambda_{\text {iso }}\right)$ could be calculated from the equation:

$$
D_{\top M}=\frac{d i s o}{d \lambda}\left(C_{x}+c_{y}\right)
$$

Where $\mathrm{D}_{\mathrm{TM}}, \mathrm{D}_{\mathrm{X}}$ and $\mathrm{D}_{\mathrm{Y}}$ are the $\mathrm{D}$ amplitudes of the total of mixture, $\mathrm{X}$ and $Y$, respectively at $\lambda_{\text {iso. }} C_{x}$ and $C_{y}$ are the concentrations of $X$ and $Y$ respectively, $d_{x}$ and $d_{y}$ are the differences of the absorptivity's of $X$ and $Y$ at the specified $d \lambda$, bx and by are the pathlengths $(1 \mathrm{~cm})$.

Since $\mathrm{X}$ and $\mathrm{Y}$ interfere at $\lambda_{\text {iso }}$ and $\mathrm{X}$ does not show any contribution at another wavelength $\lambda_{2}$, so the postulated amplitude of $Y$ in the mixture at $\lambda_{\text {iso }}$ can be calculated using its response factor between the two proposed wavelengths $\left(\lambda_{2}\right.$ and $\left.\lambda_{\text {iso }}\right)$. The amplitude corresponding to $\mathrm{X}$ could be calculated by difference between recorded amplitude corresponding to total $(\mathrm{X}+\mathrm{Y})$ and the postulated amplitude corresponding to $\mathrm{Y}$. The concentration of $\mathrm{X}$ and $\mathrm{Y}$ can be separately calculated using the same regression equation (obtained by plotting the first derivative amplitude (D) of either X or Y at $\lambda_{\text {iso }}$ against their corresponding concentrations).

\section{Applications}

This method is used in the determination of a multicomponent mixture consisting of Chloramphenicol, Dexamethasone sodium phosphate and Tetryzoline HClin eye drops in the presence of Benzalkoniuim chloride as a preservative [21]. Ascorbic acid and Rutin in pure powders, laboratory prepared mixtures, and tablets were also determined conveniently using this method [23]. The shift that occurs for the isosbestic point in derivative spectra may lead to correction of the interference that may originate from excipients.

\section{Limitations}

- Critical measurements of the amplitudes at the selected wavelength. • Greatly affected by wavelength increment. • The high noise which affects the signal to noise ratio [19].

\section{Simultaneous derivative ratio spectrophotometry $\left(\mathrm{S}^{1} \mathrm{DD}\right)$}

This method was modulated to be simultaneous by coupling with amplitude modulation theory. Before the derivatization step took place, the total concentration was firstly determined at the isoabsorption point of the ratio spectrum using the normalized spectrum as a divisor. Then derivative of these ratio spectra was obtained to remove the constant generated in the division spectrum. Moreover, optimization of the proposed method was simpler than the traditional ${ }^{1} \mathrm{DD}$ method, in which the influence of the divisor concentration was eliminated. Absorbance of this binary mixture (Aw) at a given wavelength $(\mathrm{w})$ is represented by the following equation

$$
A_{w}=a x_{w} C_{x}+a y_{w}, C_{Y}
$$

Where $\mathrm{ax}_{\mathrm{w}}$ and $\mathrm{ay}_{\mathrm{w}}$ are the absorptivities of Orphenadrine (ORP) and Paracetamol (PAR), respectively, while $\mathrm{C}_{\mathrm{x}}$ and $\mathrm{C}_{\mathrm{y}}$ are the concentrations of ORP and PAR respectively, in the mixture. As implied before, this work depends on the ratio spectra obtained using the normalized spectrum as a divisor, therefore, dividing Eq. (17) by the normalized spectra of PAR "ayw", Eq. (18) is obtained

$$
\mathbf{P}_{\mathrm{W}}-\left(a x_{\mathrm{w}} \mathrm{c}_{\mathrm{z}} / a y_{\mathrm{W}}\right)+\left(a y_{\mathrm{W}} \cdot \mathbf{C}_{\mathrm{Y}} / a y_{\mathrm{W}}\right.
$$

In Eq. (18), the used divisor "ayw" is the normalized spectrum of PAR and it is actually a spectrum of absorptivity "a" of PAR "component $Y$ " at a specified wavelength " $w$ ", and $P w=A_{w} / a_{w}$. Eq. (18) can be written as follow

$$
\mathrm{P}_{\mathrm{W}}=\left(a x_{\mathrm{w}} \mathbf{c}_{\mathrm{x}} / a y_{\mathrm{w}}\right)+\mathrm{C}_{\mathrm{Y}}
$$

As " $\mathrm{C}_{\mathrm{y}}$ " is a constant in Eq. (19), so by obtaining the first derivative of this ratio spectra, this constant will be cancelled as follow

$$
\mathbf{d P}_{\mathbf{W}}=\left(\boldsymbol{\alpha} \boldsymbol{x}_{\mathrm{w}} / \boldsymbol{a y _ { w }}\right) \mathbf{d C _ { Y }}
$$

Fig. 5 shows the obtained derivative ratio spectra of different concentrations of ORP, where measurements take place at $224 \mathrm{~nm}$. A correlation between the concentration and peak amplitude at $224 \mathrm{~nm}$ is plotted from which the concentration of ORP is determined [24].

\section{Applications}

The normalized spectrum of the divisor is used and hence no need for the tedious step of choosing the optimum concentration of divisor. This method is used in the determination of Orphenadrine and Paracetamol in tablets [24], Dimenhydrinate and Cinnarizine [25] in a combined dosage form.

\section{Limitations}

- Greatly affected by wavelength increment. - The high noise which affects the signal to noise ratio [19]. 


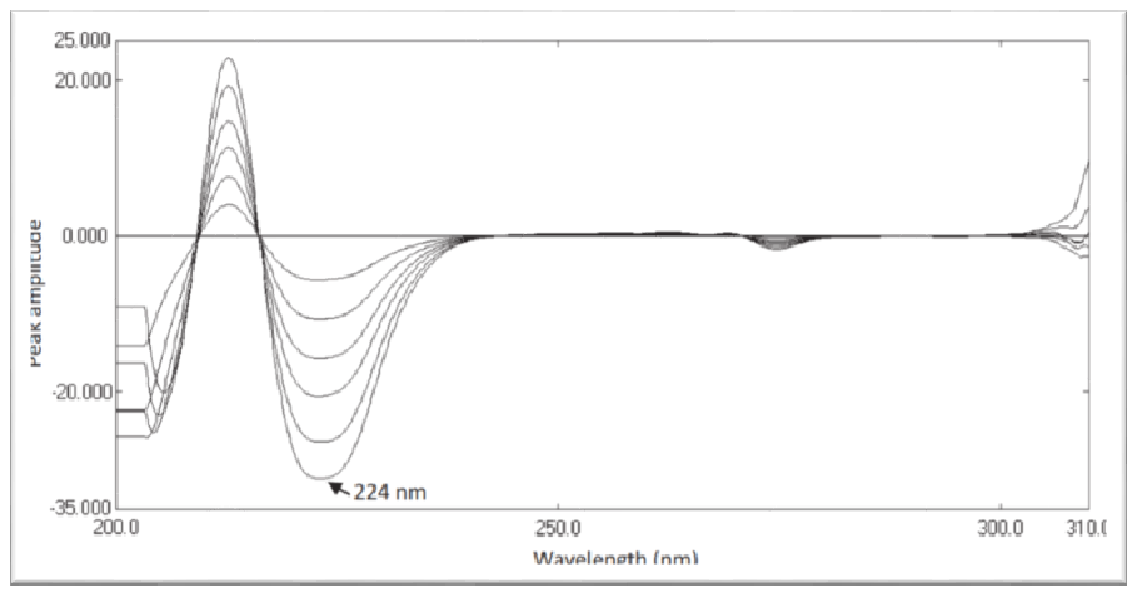

Fig. 5: First derivative of division spectra of ORP (5.0-30.0 $\mu \mathrm{g} / \mathrm{ml})$, using normalized PAR spectrum as a divisor [24]

\section{Derivative compensation ratio via regression equation}

This is a new modification of derivative compensation ratio where the regression equation computed represents the graphical method and the concentration of $(\mathrm{X})$ could be determined after substitution in it using the average of standard amplitude ratio. When the absorption curves of the two components $(\mathrm{X})$ and $(\mathrm{Y})$ overlap to a large extent or when analysis of a minor component in the presence of a major component represents a problem, the balance point or the graphical method can be adopted. Under these conditions, the absorption spectrum of a mixture of two drugs $(\mathrm{X})$ and $(\mathrm{Y})$ assumed to possess gross curve which has no characteristics of either of the pure compounds. The graphical method enhances the drawback of balance points such as tedious procedure and several uses of a standard solution of the pure sample but still has an error in measuring the concentration of the drug of interest from the graph which was eliminated by this new modification via computation of a regression equation [26-28].

The method consists of plotting the above-mentioned D1amplitude ratios of the mixture against the concentration of the drug $(x)$ in the reference cell where a line with very slight curvature is obtained. The concentration of the drug $(\mathrm{x})$ is calculated from the graph as it is the concentration corresponding to the amplitude ratio of the mixture which is equal to the standard amplitude ratio of the pure component (y) previously determined as the mean amplitude ratio $(\mathrm{Da} / \mathrm{Db})$ obtained from derivative spectra of pure (y) at different concentration.

\section{Applications}

Simpler than graphical method and lower risk of error. This method is used in determination of Sodium cromoglicate and Xylometazoline $\mathrm{HCl}$ [27].

\section{Limitations}

-Multiple steps and time-consuming. - Requires the spectral extension of one component over the other one [19].

\section{Differential dual wavelength ( $\left.{ }^{1} D^{D} \mathrm{~L}\right)$}

This novel method was applied for the analysis of binary mixture $Y$ and $\mathrm{Z}$ or ternary mixture $\mathrm{X}, \mathrm{Y}$ and $\mathrm{Z}$ using their derivative spectra at zero contribution of $X$ while the interference of the third one was eliminated by the difference between two point's shows equal amplitudes on the mixture spectra [29-32].

$$
\begin{gathered}
d A=\frac{d a}{d \lambda}={ }_{d \lambda}^{b c} \\
\frac{d A 1}{d \lambda}=\frac{d}{d \lambda}\left[a_{Y 1} b_{Y} c_{Y}\right]+\frac{d}{d \lambda}\left[a_{Z 1} b_{Z} c_{Z}\right] \\
\frac{d A Z}{d \cdot \lambda}-\frac{d}{d \cdot \lambda}\left[a_{Y 2} b_{Y} c_{Y}\right]+\frac{d}{d \lambda}\left[a_{Z 2} b_{Z} c_{Z}\right]
\end{gathered}
$$

Since the amplitudes of $\mathrm{Z}$ at the two selected wavelengths was equal

$$
\frac{d}{d \lambda}\left[a_{Z 1} b_{Z} C_{Z}\right]=\frac{d}{d \lambda}\left[a_{Z 2} b_{z} c_{Z}\right]
$$

By subtracting the amplitudes at these two points in Eq. (21) and (22), the amplitude representing $\mathrm{Z}$ would be cancelled along with any other instrumental error or any interference from the sample matrix. This could be summarized as the following:

$$
\frac{d A 1}{d \lambda} \frac{d A 2}{d \lambda}=\frac{d}{d \lambda}\left[n_{Y 1} h_{Y} C_{Y}\right]-\frac{d}{d \lambda}\left[n_{Y 2} h_{Y} C_{Y}\right]
$$

The amplitude difference between these two points on the derivative spectra of the mixture in Eq. (24) was directly proportional to the concentration of component $Y$; while for component $\mathrm{Z}$ the amplitude difference equals to zero and there is no contribution of $X$ at these two wavelengths. This novel method was applied when the principle of the conventional dual-wavelength is not fulfilled on the zero-order absorption spectrum since no two points showing equal absorbance of the interfering substance and so it could be applied on the derivative spectrum with equal amplitudes of the interfering substance.

The advantage of this novel method over conventional dualwavelength method is that it can be applied on derivative spectrum of the mixture and thus enhances resolution between peaks. The influence of one component in the mixtures either binary or ternary can be eliminated by applying derivative technique while the interference of the third component can be eliminated by the difference between two points showing equal amplitudes of the interfering substance on the mixture spectra.

\section{Applications}

Applied when the principle of the conventional dual-wavelength isn't fulfilled on the zero-order absorption spectrum. This method is used in the determination of lidocaine $\mathrm{HCl}$, fluocortolone pivalate and chlorquinaldol in pharmaceutical formulations with no interference from excipients [33].

\section{Limitations}

-Critical measurements of the amplitudes at the selected wavelength

\section{Differential derivative ratio ( $\left.{ }^{1} \mathrm{DR}\right)$}

Novel successive resolution technique was applied using the derivative technique to resolve the severely overlapped spectra followed by differential derivative ratio method using derivative spectra instead of the zero order spectra in the conventional derivative ratio. This novel method was applied for the analysis of ternary mixtures $\mathrm{X}, \mathrm{Y}$ and $\mathrm{Z}$ where the zero order absorption spectra of cited components were severely overlapped while the first derivative spectrum of $\mathrm{Y}$ and $\mathrm{Z}$ were overlapped at zero contribution of X. In the new approach, derivative 
ratio was applied using the first derivative spectra. For the determination of $Y$, the ratio spectra of the derivative spectrum of the mixture is divided by the derivative spectrum of pure $\mathrm{Z}$ as a divisor.

$$
\begin{gathered}
\frac{d a}{d \lambda}=\frac{d a}{d \lambda} b c \\
\frac{d A}{d \lambda}=\frac{d}{d \lambda}\left\{a_{Y} b_{Y} C_{Y}\right\}+\frac{d}{d \lambda}\left\{a_{Z} b_{Z} C_{Z}\right\} .
\end{gathered}
$$

Division using first derivative spectrum of pure $\mathrm{Z}$ as a divtsor $\frac{d}{d \lambda}\left\{a_{Z} b_{Z} C_{Z}\right\}$

$$
\frac{\frac{d}{d \lambda}\{A\}}{\left\{\frac{d a_{Z}}{d \lambda b_{Z} C_{Z^{\prime}}}\right\}}=\frac{\frac{d}{d \lambda}\left\{a_{Y} b_{Y} c_{Y}\right\}}{\frac{d}{d \lambda}\left\{a_{Z} b_{Z} C_{Z^{\prime}}\right\}}+\text { constant }
$$

The obtained ratio spectrum thus obtained in Eq. (21) are differentiated with respect to wavelength

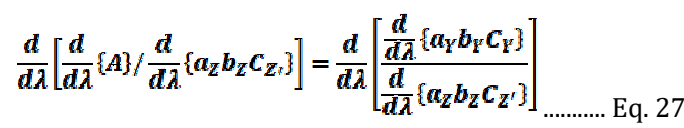

The above equation could be simplified to:

$$
\frac{d}{d \lambda}\left[\frac{\frac{d}{d \lambda}\{A\}}{\frac{d}{d \lambda}\left\{a_{Z}\right\}}\right]-\frac{d}{d \lambda}\left[\frac{\frac{d}{d \lambda}\left\{a_{Y} b_{Y} C_{Y}\right\}}{\frac{d}{d \lambda}\left\{a_{Z}\right\}}\right]_{\ldots \ldots . . . \text { Eq. } 28}
$$

Eq. (24) indicated that the derivative ratio spectrum of the mixture was dependent only on the values of $C_{Y}$, and is independent of the value of $\mathrm{C}_{Z}$ in the mixture thus the first derivative values at a given wavelength are plotted against $\mathrm{C}_{Y}$. The concentration of $\mathrm{Y}$ was determined using the regression equation representing the amplitude of the ratio spectra versus the corresponding concentration of $\mathrm{Y}$. On the other side, $\mathrm{Z}$ could be analysed via the same procedures using $\mathrm{Y}$ as a divisor.

Differential derivative ratio method for the resolution of ternary mixtures had an advantage over derivative ratio method that it was more reliable with respect to utility and sensitivity without searching for the critical point either zero crossing point or coincident point for the separated peaks and the maximum amplitude of the separated peaks could be measured [33]. In addition, $\mathrm{D}^{1} \mathrm{DR}$ overcame the main disadvantages of successive derivative ratio spectrophotometry for the analysis of ternary mixture that it required the use of multiple manipulating steps and multiple divisors [34].

\section{Applications}

Used for the analysis of the ternary mixture using single divisor without searching the critical point at the separated peaks. This method is used in the determination of lidocaine $\mathrm{HCl}$, fluocortolone pivalate and chlorquinaldol in a pharmaceutical dosage form [34].

\section{Limitations}

-Affected by wavelength increment [19].

\section{Successive derivative subtraction method (SDS)}

In a ternary mixture of $\mathrm{X}, \mathrm{Y}$ and $\mathrm{Z}$, where the spectrum of $\mathrm{Z}$ was more extended than $\mathrm{Y}$ which was in turn more extended than $\mathrm{X}$, elimination of one component after the other was possible using successive derivative subtraction at zero contribution of the interfering one. Then the less extended drug was determined in a mixture of three compounds X, Y and Z. If Beer's law was obeyed in the whole wavelength range used and by considering the path length as $1 \mathrm{~cm}$, the absorbance of the ternary mixture at each wavelength could be written as:

$$
\left[\mathbf{A}_{\mathrm{m}}\right]=\left[\mathbf{a}_{\mathbf{X}} \mathbf{C}_{\mathbf{X}}\right]+\left[\mathbf{a}_{\mathbf{Y}} \mathbf{C}_{\mathbf{Y}}\right]+\left[\mathbf{a}_{\mathbf{Z}} \mathbf{C}_{\mathbf{Z}}\right] . \text {. Eq. } 29
$$

Am was the vector of the absorbance of the mixture, $a x, a y, a z$ were the absorptivity vectors of $\mathrm{X}, \mathrm{Y}$ and $\mathrm{Z}$ and $\mathrm{C}_{\mathrm{X}}, \mathrm{C}_{\mathrm{Y}}$ and $\mathrm{C}_{\mathrm{Z}}$ were the concentrations of $\mathrm{X}, \mathrm{Y}$ and $\mathrm{Z}$, respectively.
If the first derivative of Eq. (29) was taken, Eq. (30) would be obtained

$$
\left(\frac{d}{d \lambda}\right)\left[A_{\mathrm{m}}\right]=\left(\frac{d}{d \lambda}\right)\left[\mathrm{a}_{\mathrm{X}} \mathrm{C}_{\mathrm{X}}\right]+\left(\frac{d}{d \lambda}\right)\left[\mathrm{a}_{\mathrm{Y}} \mathrm{C}_{\mathrm{Y}}\right]+\left(\frac{d}{d \lambda}\right)\left[\mathrm{a}_{\mathrm{Z}} \mathrm{C}_{\mathrm{Z}^{\prime}}\right]
$$

Dividing Eq. (30) with the first derivative of spectrum $\mathrm{Z}$ as a divisor $(d / d \lambda)\left[a_{z} C_{z}\right]$, so the following equation was obtained:

$$
\frac{\left(\frac{d}{d \lambda}\right)\left[\mathrm{a}_{\mathrm{X}} \mathrm{C}_{\mathrm{X}}\right]}{\left(\frac{d}{d \lambda}\right)\left[\mathrm{a}_{\mathrm{Z}} \mathrm{C}_{Z^{\prime}}\right]}+\frac{\left(\frac{d}{d \lambda}\right)\left[\mathrm{a}_{\mathrm{Y}} \mathrm{C}_{\mathrm{Y}}\right]}{\left(\frac{d}{d \lambda}\right)\left[\mathrm{a}_{\mathrm{Z}} \mathrm{C}_{Z^{\prime}}\right]}+\text { constant }
$$

The constant value $\left\{\left(\frac{d}{d \lambda}\right)\left[\mathrm{a}_{\mathrm{z}} \mathrm{C}_{z}\right] /\left(\frac{d}{d \lambda}\right)\left[\mathrm{a}_{Z} \mathrm{C}_{Z^{\prime}}\right]\right\}$ could be determined directly from the $\left(\frac{d}{d \lambda}\right)\left[A_{m}\right]$ spectrum by the straight line that was parallel to the wavelength axis in the region where $\mathrm{Z}$ was extended. Constant multiplication method had been established as a new approach in which $\mathrm{Z}$ could be determined by multiplying $\left(\frac{a}{d \lambda}\right)\left[\mathrm{a}_{\mathrm{Z}} \mathrm{C}_{Z^{\prime}}\right]$

divisor by the previously obtained constant, therefore we could obtain the $\mathrm{D}^{1}$ spectrum of $\mathrm{Z}$ again [35-37]. This could be summarized as follows:

$$
\left\{\frac{\left(\frac{d}{d \lambda}\right)\left[\mathrm{a}_{\mathrm{z}} \mathrm{C}_{\mathrm{Z}}\right]}{\left(\frac{d}{d \lambda}\right)\left[\mathrm{a}_{\mathrm{Z}} \mathrm{C}_{Z^{\prime}}\right]}\right\} *\left(\frac{d}{d \lambda}\right)\left[\mathrm{a}_{\mathbf{Z}} \mathrm{C}_{Z^{\prime}}\right]
$$

The concentration of $\mathrm{Z}$ was calculated by using the regression equation representing the linear relationship between the

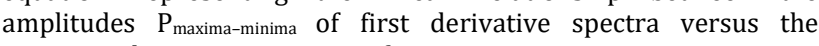
corresponding concentrations of $\mathrm{Z}$.

By subtracting the measured value of the constant from the ratio spectrum Eq. (31), then multiplying the new spectrum by $\left(\frac{a}{a \lambda}\right)\left[a_{z} C_{z^{\prime}}\right]$ $(\mathrm{X}+\mathrm{Y})$ can be obtained. This could be summarized in the following equations:

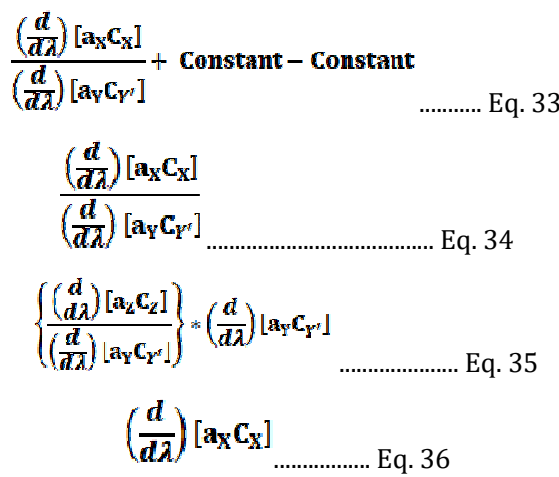

The concentration of $\mathrm{X}$ was calculated by using the regression equation representing the linear relationship between the

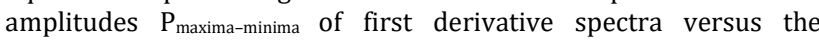
corresponding concentrations of X. Successive derivative subtraction had the advantage that it could be used when there was certain overlap of the interfering drug (s) in the mixture at the extended parts and this overlapping could be resolved by the derivative technique in contrary of successive ratio subtraction which was valid for analysis of drugs when the interfering drug (s) showed zero contribution at the extended region.

\section{Applications}

The $\mathrm{D}^{1}$ spectrum of each component in the mixture was obtained as that of pure one without any interference from other components in the mixture. Higher amplitude values and subsequently larger slope and maximum sensitivity in contrary to those obtained by applying the derivative technique. This method was used in the determination of lidocaine $\mathrm{HCl}$, calcium desolates and dexamethasone acetatein eye drops [39], determination of Chloramphenicol, dexamethasone sodium phosphate and tetryzoline HClin a pharmaceutical mixture [33] Chloramphenicol and dexamethasone sodium phosphate were 
also quantified in the presence of non labelled interfering substances [40].

\section{Limitations}

- Limited for ternary mixtures of X, Y and Z, where the D spectrum of $\mathrm{Z}$ is more extended than $\mathrm{Y}$ which was in turn more extended than $\mathrm{X}$. - The need of a different divisor for each component and utilizing different ratio spectra [19].

\section{Derivative transformation (DT)}

This novel method is applied in order to transform the derivative spectrum to its original zero order absorption spectrum [38]. Dividing the obtained first derivative spectrum of $X$ by the derivative of normalized spectrum of pure $X$ and multiplying the obtained spectrum or its amplitude (which is a constant represents its concentration) by the normalized spectrum of pure $\mathrm{X}\left(\mathrm{a}_{\mathrm{x}}\right)$; the zeroorder absorption spectrum of $\mathrm{X}[\mathrm{ax} \mathrm{C}]$ is obtained that could be used either for resolution or determination of $\mathrm{X}$. This can be formulated in the following equations:

$$
\begin{gathered}
\frac{\left(\frac{d}{d \lambda}\right)\left[\mathrm{a}_{\mathrm{x}} \mathrm{c}_{\mathrm{X}}\right]}{\left(\frac{d}{d \lambda}\right)\left[\mathrm{a}_{\mathrm{X}}\right]} \\
\mathbf{C}_{\mathrm{X}}+\left[\mathrm{a}_{\mathrm{X}}\right] \\
{\left[\mathrm{a}_{\mathrm{X}} \mathbf{C}_{\mathrm{X}}\right]}
\end{gathered}
$$

These steps could be summarized by using a decoding spectrum $\left[\mathrm{a}_{\mathrm{x}}\right] /\left(\frac{d}{d \lambda}\right)\left[\mathrm{a}_{\mathrm{x}}\right]$ which a new spectrum is obtained by dividing the normalized spectrum by its derivative. After multiplying the derivative spectrum of $\mathrm{X}$ by the decoding spectrum; the original zero order absorption spectrum of $\mathrm{X}$ is obtained.

$$
\left[\mathrm{a}_{\mathrm{X}} \mathrm{c}_{\mathrm{X}}\right]=\left(\frac{d}{d \lambda}\right)\left[\mathrm{a}_{\mathrm{X}} \mathbf{c}_{\mathrm{X}}\right] /\left(\frac{d}{d \lambda}\right)\left[\mathrm{a}_{\mathrm{X}}\right]
$$

This decoding spectrum is the same for all the concentrations of pure $X$.

\section{Applications}

It transforms first order spectrum into zero order absorption spectra by their corresponding decoding spectra. High accuracy, reproducibility, sensitivity and ensures the spectrum typical to that of a pure form in its spectral profile. This method is used in determination of Mebeverine hydrochloride and Chlordiazepoxide [38].

\section{Limitations}

This method is complementary to derivative spectrophotometric methods [19].

\section{CONCLUSION}

Derivative spectrophotometry was a commonly used method in UV spectroscopy and recently several advancements in the statistical soft wares led a way to the design of a variety of derivative spectrophotometric techniques. Incorporation of the mathematical equations leads to discovering new pathways for the application of Ultraviolet-visible spectroscopy in the field of analysis. Compared to the conventional reported Ultraviolet-visible spectrophotometric methods for mixtures, these methods are more advantageous regarding the simplicity of operation and sensitivity of measurement. These methods do not require sophisticated experimental steps and elaborate treatment. The developed methods have the specific advantage of separation methods and obviously can be applied in complex mixtures with severely overlapped spectra and partially. The developed methods show good precision and accuracy in the determination of drug combinations in pharmaceutical formulations; therefore, these are excellent alternatives to other hyphenated analytical techniques. Compared to conventional methods these modified methods are more timesaving, economical and sensitive.

\section{ACKNOWLEDGMENT}

The authors are grateful to GITAM Deemed to be University, India for supporting the article.

\section{AUTHORS CONTRIBUTIONS}

All the author have contributed equally

\section{CONFLICT OF INTERESTS}

All authors declare that there is no conflict of interest related with this article.

\section{REFERENCES}

1. Somer L. Analytical absorption spectrophotometry in the visible and ultraviolet. 1st ed. Amsterdam (NL): Elsevier Science publishers; 1989.

2. Rojas FS, Ojeda CB. Recent development in derivative ultraviolet/visible absorption spectrophotometry 2004-2008, a review. Anal Chim Acta 2009;635:22-44.

3. Heinz HP, Grinter HC. UV-VIS spectroscopy and its applications. 1st ed. Berlin (GR): Springer Laboratory; 1992.

4. Beckett AH, Stenlake JB. Practical pharmaceutical chemistry. Part 2. $2^{\text {nd }}$ ed. New Delhi (IN): CBS publishers; 2007.

5. Vladimir SS, Alexander IK, Eugene VR, Irina GD. Derivative spectrophotometry and PAM-fluorescence in comparative biochemistry. 1st ed. Dordrech (UK): Springer Nature; 2015.

6. Joanna K. Basic principles and analytical application of derivative spectrophotometry. In. Jamal U. editor. Macro to Nano Spectroscopy. $1^{\text {st }}$ ed. Croatia: InTech; 2012. p. 253-68.

7. Basilio M. Determination of diazepam and otilonium bromide in pharmaceuticals by ratio-spectra derivative spectrophotometry. Fresenius J Anal Chem 1997;357:1179-84.

8. Hamed MELF, Mokhtar MM, Hammad SF, Elsheikh SH. Different ratio spectra methods for simultaneous determination of olmesartan medoxomil, hydrochlorothiazide and amlodipine besylate. J Innovations Pharm Biol Sci 2016;3:166-81.

9. Abdel AYES, Najeb AELS. Recent developments of derivative spectrophotometry and their analytical applications. Anal Sci 2005;21:595-614.

10. R'afat MN, Mahmoud MI, Alaa AS, Nahed TS. Double divisor means centering of ratio spectra as a developed spectrophotometric method for the analysis of five-component mixture in drug analysis. J Saudi Chem Soc 2017;21:S283-S92.

11. Dinç E. The spectrophotometric multicomponent analysis of a ternary mixture of ascorbic acid, acetylsalicylic acid and paracetamol by the double divisor-ratio spectra derivative and ratio spectra-zero crossing methods. Talanta 1999;48:1145-57.

12. Fitria A, Muchlisyam B, Siti MS. Development and validation of double divisor ratio spectra derivative spectrophotometry method for ternary mixture of guaifenesin, dextromethorphan $\mathrm{HBR}$, and diphenhydramine $\mathrm{HCl}$ in the tablet dosage form. Asian J Pharm Clin Res 2018;11:1-3.

13. Erdal D, Feyyaz O. Application of a new spectrophotometric method for the analysis of a ternary mixture containing metamizol, paracetamol and caffeine in tablets. Anal Chim Acta 1998;395:93-106.

14. Abbas A, Morteza B. Mean centering of ratio spectra as a new spectrophotometric method for the analysis of binary and ternary mixtures. Talanta 2005;66:712-20.

15. Lotfy HM, Tawakkol SM, Fahmy NM, Shehata MA. Successive spectrophotometric resolution as a novel technique for the analysis of ternary mixtures of pharmaceuticals. Spectrochim Acta Part A 2014;121:313-23.

16. Lotfy HM, Tawakkol SM, Fahmy NM, Shehata MA. Validated stability indicating spectrophotometric methods for the determination of lidocaine hydrochloride, calcium dobesilate, and dexamethasone acetate in their dosage forms. Anal Chem Lett 2013;3:201-25.

17. Lotfy HM, Mohamed D, Mowaka S. A comparative study of smart spectrophotometric methods for simultaneous determination of sitagliptin phosphate and metformin hydrochloride in their binary mixture. Spectrochim Acta Part A 2015;149:441-51.

18. Lotfy HM, Aboul Alamein AM, Hegazy MA. Quantitative analysis of the cholesterol-lowering drugs ezetimibe and simvastatin in pure powder, binary mixtures, and a combined dosage form by spectrophotometry, chemometry, and high-performance column liquid chromatography. J AOAC Int 2010;39 Suppl 5:1844-55. 
19. Hayam Ml, Sarah SS. Recent development in ultraviolet spectrophotometry through the last decade (2006-2016): a review. Int J Pharm Pharm Sci 2016;8:40-56.

20. Ramzia I, Bagary El, Shereen M, Ehab F Elkady, Maria A, Attallah. Validated spectrophotometric methods for determination of weakly uv absorbed perindopril arginine in bulk and combined dosage form. Anal Chem Lett 2017;6:766-82.

21. Lotfy HM, Saleh SS, Hassan NY, Salem H. A comparative study of novel spectrophotometric methods based on isosbestic points; application on a pharmaceutical ternary mixture. Spectrochim Acta Part A 2014;126:112-21.

22. Lotfy HM, Hegazy MA, Mowaka S, Mohamed EH. Validated spectrophotometric methods for simultaneous determination of omeprazole, tinidazole and doxycycline in their ternary mixture. Spectrochim Acta Part A 2016;153:321-32.

23. Darwish HW, Bakheit AH, Naguib IA. Comparative study of novel ratio spectra and isoabsorption point based spectrophotometric methods: application on a binary mixture of ascorbic acid and rutin. J Anal Methods Chem 2016;2:1-12.

24. Yehia AM, Abd El-RMK. Application of normalized spectra in resolving a challenging orphenadrine and paracetamol binary mixture. Spectrochim Acta Part A 2015;138:21-30.

25. Lamie NT, Yehia AM. Development of normalized spectra manipulating spectrophotometric methods for simultaneous determination of dimenhydrinate and cinnarizine binary mixture. Spectrochim Acta Part A 2015;150:142-50.

26. Erk N. Analysis of binary mixtures of losartan potassium and hydrochlorothiazide by using high-performance liquid chromatography, ratio derivative spectrophotometric and compensation technique. J Pharm Biomed Anal 2001;24:603-61.

27. Lotfy HM, Saleh SS, Hassan NY, Elgizawy SM. Spectrophotometric and chromatographic methods for the determination of a binary mixture of sodium cromoglicate and xylometazoline hydrochloride. Anal Chem Indian J 2013;13:152-60.

28. Wahbi AAM, Abdel RO, Gazy AA, Mahgoub H, Moneeb MS. Spectrophotometric determination of omeprazole, lansoprazole and pantoprazole in pharmaceutical formulations. J Pharm Biomed Anal 2002;30:1133-42.

29. Ramadan NK, Mohamed HM, Moustafa AA. Simultaneous determination of rabeprazole sodium and domperidone. J Appl Pharm Sci 2011;1:73-80.

30. Abdelwahab NS. Spectrophotometric methods for simultaneous determination of carvedilol and hydrochlorothiazide in the combined dosage form. Arabian J Chem 2016;9:S355-60.
31. Sawsan AAR, Manal MF, Manal KD, Hala EZ, Zeinab An. Spectrophotometric methods for simultaneous determination of gatifloxacin and dexamethasone in their binary mixture. Indo Am J Pharm Res 2015;5:3048-57.

32. Berzas NJJ, Guiberteau CC, Salinas F. Spectrophotometric resolution of ternary mixtures of salicylaldehyde, 3hydroxybenzaldehyde and 4-hydroxybenzaldehyde by the derivative ratio spectrum-zero crossing method. Talanta 1992;39:547-53.

33. Afkhami A, Bahram M. Successive ratio-derivative spectra as a new spectrophotometric method for the analysis of ternary mixtures. Spectrochim Acta Part A 2005;61:869-77.

34. Lotfy HM, Tawakkol SM, Fahmy NM, Shehata A. A comparative study of novel spectrophotometric resolution techniques applied for pharmaceutical mixtures with partially or severely overlapped spectra. Spectrochim Acta Part A 2015;136:937-52.

35. Lotfy HM. Determination of simvastatin and ezatimib in combined tablet dosage form by constant center spectrophotometric method. Int $\mathrm{J}$ Pharm Pharm Sci 2012;4:673-9.

36. Lotfy HM, Hegazy MA. Simultaneous determination of some cholesterol-lowering drugs in their binary mixture by novel spectrophotometric methods. Spectrochim Acta Part A 2013;113:107-14.

37. Lotfy HM, Saleh SS, Hassan NY, Elgizawy SM. Univariate versus multivariate spectrophotometric methods for simultaneous determination of complex binary mixtures with overlapped spectra: a comparative study. Anal Chem Lett 2013;3:70-84.

38. Lotfy HM, Fayez YM, Michael AM, Nessim CK. Simultaneous determination of mebeverine hydrochloride and chlordiazepoxide in their binary mixture using novel univariate spectrophotometric methods via different manipulation pathways. Spectrochim Acta Part A 2016;115:11-20.

39. Saleh SS, Lotfy HM, Hassan NY, Salem H. A comparative study of progressive versus successive spectrophotometric resolution techniques applied for pharmaceutical ternary mixtures. Spectrochim Acta Part A 2014;132:239-48.

40. Hegazy MA, Lotfy HM, Rezk MR, Omran YR. Novel spectrophotometric determination of chloramphenicol and dexamethasone in the presence of non-labeled interfering substances using univariate methods and multivariate regression model updating. Spectrochim Acta Part A 2015;140:600-13. 